\title{
Designing on-demand education for simultaneous development of domain-specific and self-directed learning skills
}

Citation for published version (APA):

Taminiau, E. M. C., Kester, L., Corbalan, G., Spector, J. M., Kirschner, P. A., \& Van Merrienboer, J. J. G. (2015). Designing on-demand education for simultaneous development of domain-specific and selfdirected learning skills. Journal of Computer Assisted Learning, 31(5), 405-421. https://doi.org/10.1111/jcal.12076

Document status and date:

Published: 01/10/2015

DOI:

10.1111/jcal.12076

Document Version:

Publisher's PDF, also known as Version of record

\section{Document license:}

Taverne

Please check the document version of this publication:

- A submitted manuscript is the version of the article upon submission and before peer-review. There can be important differences between the submitted version and the official published version of record.

People interested in the research are advised to contact the author for the final version of the publication, or visit the DOI to the publisher's website.

- The final author version and the galley proof are versions of the publication after peer review.

- The final published version features the final layout of the paper including the volume, issue and page numbers.

Link to publication

\footnotetext{
General rights rights.

- You may freely distribute the URL identifying the publication in the public portal. please follow below link for the End User Agreement:

www.umlib.nl/taverne-license

Take down policy

If you believe that this document breaches copyright please contact us at:

repository@maastrichtuniversity.nl

providing details and we will investigate your claim.
}

Copyright and moral rights for the publications made accessible in the public portal are retained by the authors and/or other copyright owners and it is a condition of accessing publications that users recognise and abide by the legal requirements associated with these

- Users may download and print one copy of any publication from the public portal for the purpose of private study or research.

- You may not further distribute the material or use it for any profit-making activity or commercial gain

If the publication is distributed under the terms of Article $25 \mathrm{fa}$ of the Dutch Copyright Act, indicated by the "Taverne" license above, 


\title{
Journal of Computer Assisted Learning
}

\section{Designing on-demand education for simultaneous development of domain-specific and self-directed learning skills}

\author{
E.M.C. Taminiau,* L. Kester, * G. Corbalan,‡ J.M. Spector,§ P.A. Kirschner* \& \\ J.J.G. Van Merriënboerף \\ *Open Universiteit in the Netherlands, Heerlen, The Netherlands \\ ¥Netherlands Organisation for Applied Scientific Research TNO, Soesterberg, The Netherlands \\ §University of North Texas, Denton, TX, USA \\ IMaastricht University, Maastricht, The Netherlands
}

\begin{abstract}
On-demand education enables individual learners to choose their learning pathways according to their own learning needs. They must use self-directed learning (SDL) skills involving self-assessment and task selection to determine appropriate pathways for learning. Learners who lack these skills must develop them because SDL skills are prerequisite to developing domain-specific skills. This article describes the design of an on-demand learning environment developed to enable novices to simultaneously develop their SDL and domain-specific skills. Learners received advice on their self-assessments and their selections of subsequent learning tasks. In the domain of system dynamics - a way to model a dynamic system and draw graphs depicting the system's behaviour over time - advice on self-assessment is provided in a scoring rubric containing relevant performance standards. Advice on task selection indicates all relevant task aspects to be taken into account, including recommendations for suitable learning tasks which meet the individual learner's needs. This article discusses the design of the environment and the learners' perceptions of its usefulness. Most of the times, the learners found the advice appropriate and they followed it in $78 \%$ of their task selections.
\end{abstract}

Keywords advice, domain-specific skills, on-demand education, second-order scaffolding, self-directed learning skills.

\section{Introduction}

In on-demand education, it is the individual learner who determines his/her own learning pathway accord-

Accepted: 16 May 2014

Correspondence: Elisabeth Taminiau, Centre for Learning Sciences and Technologies, Open University of The Netherlands, P.O. Box 2960, Heerlen 6401 DL, The Netherlands. Email: b.taminiau @gmail.com ing to his/her own learning needs (Hannafin, 1984; Topping, 2003; Van Merriënboer, 1997; Van Merriënboer \& Kirschner, 2013; Van Merriënboer et al., 2006) following a cyclical learning model (see Figure 1). First, they perform a task. Then, they assess their task performance so as to identify their learning needs. Third, they select a subsequent task that best helps them to fulfill their learning needs and improve their performance. Often the learners can follow the cyclical model at their own pace (Bell \& Kozlowski, 

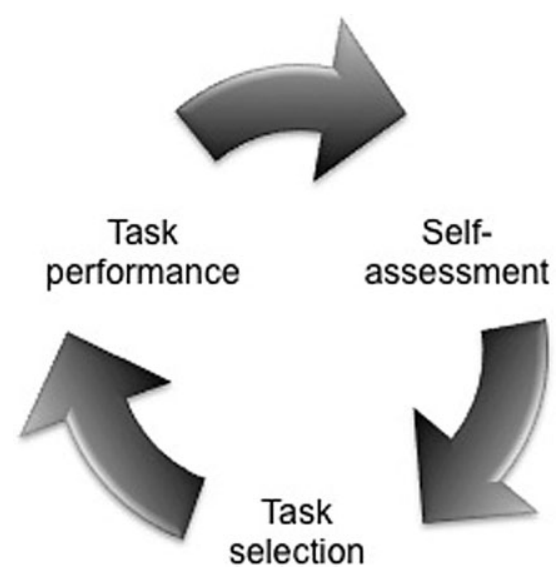

Figure 1 Cyclical Learning Model of On-Demand Education

2002; Vandewaetere \& Clarebout, 2011). This approach allows high-ability learners who successfully and quickly performed a task to proceed without unnecessary delays and prevents them from becoming demotivated or disinterested. On the other hand, it allows low-ability learners to take their time to study and practise without having to hurry to meet time constraints that could hamper their learning progress (Gerjets, Scheiter, Opfermann, Hesse, \& Eysink, 2009). Therefore, it is important to not only let learners control the direction of their learning pathway but their learning pace too.

Performing appropriate tasks that fit individual learning needs can improve domain-specific skills development. Therefore, an on-demand learning environment in which task selections are properly adapted to the learners' learning needs is more efficient for learning domain-specific skills than a type of learning environment in which tasks are carried out in a fixed order (Camp, Paas, Rikers, \& Van Merriënboer, 2001; Salden, Paas, Broers, \& Van Merriënboer, 2004). An on-demand environment allows learners with welldeveloped domain-specific skills to choose more complex tasks and learners with less developed domain-specific skills to choose less complex ones. Other benefits of such an environment are increased learner motivation (Kinzie \& Sullivan, 1989; Schnackenberg \& Sullivan, 2000; Topping, 2003) and more positive feelings of control and responsibility over one's learning pathway (Corbalan, Kester, \& Van Merriënboer, 2006; Topping, 2003). These benefits may positively affect learning outcomes.
To deal with on-demand education, learners need to have self-directed learning (SDL) skills involving selfassessment skills and task-selection skills, otherwise they will not be able to choose an appropriate learning pathway (Bjork, 1999). Learners lacking SDL skills might not be capable of handling this type of education; that is, they may not be able to choose appropriate learning pathways. This may discourage or even hamper the development of domain-specific skills. Therefore, learners who do not possess SDL skills need to develop them in order to be able to acquire domainspecific skills in an on-demand environment.

There are different theories on how to design instructions for training programs aimed at either the development of particular SDL skills or the acquisition of domain-specific skills. In addition, there are models on how to design instruction for particular parts of on-demand learning environments. However, to our knowledge, no prescriptive theories are available for developing an entire on-demand learning environment in which novice learners are helped to simultaneously develop both domain-specific skills and SDL skills. Therefore, a literature review is conducted and relevant theories and models are combined in order to give recommendations on how such an on-demand learning environment should best be designed.

There are two approaches to acquiring both SDL skills and domain-specific skills. One approach is a part-task approach where not all the components of both types of skills have to be acquired at the same time; nor do all components of both types of skills have to be acquired simultaneously (Van Merriënboer \& Kester, 2008). According to the part-task approach, learners first gradually acquire one of the skills, component by component, before gradually acquiring the other skills. In other words, in a part-task training setting, the skill components and skills are acquired in isolation. A drawback of this approach is that learners do not learn to coordinate the different skill components and will often not be able to transfer the acquired skills to new situations (Van Merriënboer \& Kester, 2008; Van Merriënboer, Kirschner, \& Kester, 2003).

In contrast, a whole-task approach requires learners to acquire all of the components of both the SDL skills and the domain-specific skills simultaneously in a simplified model of a real-life setting (Van Merriënboer, 1997; Van Merriënboer \& Kester, 2008; Van Merriënboer \& Kirschner, 2013). The learners deal 
with simplified whole tasks that gradually become more complex. In this way, they learn to coordinate all skill components of both types of skills which enhance the transfer of the acquired skills to unfamiliar situations. Although it might seem difficult to acquire two types of complex skills simultaneously, this approach results in higher learning outcomes than a part-task approach (Van Merriënboer \& Kester, 2008). Therefore, a whole-task approach is preferable in an on-demand learning environment where learners have to acquire and coordinate SDL skills and domainspecific skills.

However, simultaneously acquiring two types of complex skills can cognitively overload a learner, even when the tasks are performed in a simplified version of the real-life setting. Therefore, providing support and/or guidance is necessary (Clark \& Mayer, 2008; Ross, Morrison, \& O'Dell, 1989; Van Merriënboer \& Kester, 2008). In the project reported in this article, an on-demand learning environment is designed to develop both SDL skills and domain-specific skills simultaneously while learners receive necessary support and guidance for choosing suitable learning pathways. This advice might help learners acquire SDL skills while also improving the acquisition of domainspecific skills. The more capable the learner is in choosing an appropriate learning pathway, the better the chosen learning tasks will fit his/her learning needs which enhances the acquisition and development of domain-specific skills.

Although there are many SDL skills, this paper emphasizes self-assessment skills and task-selection skills (Brand-Gruwel, Kester, Kicken, \& Kirschner, 2014; Ellinger, 2004; Kicken, Brand-Gruwel, Van Merriënboer, \& Slot, 2009), because these skills are especially useful to deal with the two steps of the cyclical learning model (see Figure 1) of self-assessing performance and selecting new tasks. The theoretical underpinnings for the design of an on-demand learning environment that provides advice to allow learners to acquire these SDL skills and domain-specific skills simultaneously will be given. Next, the learners' perceptions of the advice in such a learning environment will be presented. The findings on learners' perceptions will be discussed and points of improvement for the on-demand environment with its advice are provided, including ideas for future research. Finally, the main conclusions are provided.

\section{Self-assessment skills}

In the self-assessment phase of the cyclical model (Figure 1), learners must assess their task performance. Appropriate self-assessment predicts how well a learner will perform a task similar to a recently performed task (Bjork, 1999; Topping, 2003). It indicates the level of the domain-specific skills and the available knowledge at a certain moment in time. In addition, good self-assessment informs the learner what specific aspects of these skills and knowledge need to be improved, and, thus, what their learning needs are.

Inappropriate self-assessments can be caused by learners underestimating or overestimating their level of domain-specific skills and knowledge. Overestimation can lead to strong perceived self-efficacy, and, therefore, to an inaccurate judgment of the quality of performance (Bandura, 1994; Bjork, 1999). Overestimators might set goals that are too challenging and believe that they can reach these goals. In contrast, underestimation leads to low perceived self-efficacy (Bandura, 1994). Underestimators may not know when they have considerably improved, and might set unchallenging goals because they think they will not successfully reach a challenging goal (Bjork, 1999). These incorrect self-assessments negatively affect the determination of learning needs. As a consequence, the learning pathway might be chosen incorrectly and may not optimally improve learning.

To make a correct self-assessment, learners should take performance standards into account (Van Merriënboer, 1997; Van Merriënboer \& Kirschner, 2013). Performance standards are criteria for good performance; performance objectives specify these standards. For example, a baker has the objectives of baking ordered bread for a restaurant and delivering it on time. This might result in performance standards such as: (a) the order is checked as to which type of bread is ordered and how much of it is ordered; (b) all ingredients are gathered before starting to make the dough; (c) the dough is made according to the recipe; (d) the oven is set to the accurate temperature; (e) the bread is appropriately baked; and (f) the bread is delivered on time.

Assessors need to have knowledge about the domain and the performance standards in this domain (Kalyuga, 2009). Consequently, novices in a domain might not have enough domain-specific knowledge and 
skills to accurately self-assess their performance which hinders determination of their learning needs and the choice of an appropriate learning pathway. Therefore, these learners need to be helped to appropriately selfassess their task performance. A possible way to do this is by providing advice on self-assessment (Van Merriënboer, 1997; Van Merriënboer \& Kirschner, 2013). As performance standards must be taken into account for correct self-assessment, novices should be provided with advice that informs them what the standards are and how they should be taken into account for accurate self-assessment.

\section{Task-selection skills}

Another important SDL skill is task selection, which enables learners to select a task by themselves that best fits their learning needs as provided by the selfassessment (Figure 1). By carrying out a suitable task, learners should be able to improve their domainspecific skills. First, task selection includes focusing on relevant task aspects such as available support and difficulty levels for selecting a subsequent task. A learner needs to determine if the subsequent task should contain less support, equal support, or more support, or if it should be less difficult, equally difficult or more difficult than the previous task. To do this, learners must take their self-assessment into account because the quality of their performance is a good indicator of their domain-specific skills development (Van Merriënboer, 1997; Van Merriënboer \& Kirschner, 2013). Along with self-assessment, learners may consider their invested mental effort (the cognitive capacity used for accomplishing a learning task) when selecting a subsequent task (Van Merriënboer et al., 2006). This mental effort is determined by asking learners to answer this question: 'How much mental effort did you invest to perform the task?' (Paas, Tuovinen, Tabbers, \& Van Gerven, 2003). By using self-assessment results and invested mental effort, learners can estimate the quality of performance and the level of expertise. For example, if learner A invests a high amount of mental effort and performs a task well, and learner B invests a low amount of mental effort but performs this task equally well, then learner $\mathrm{B}$ is assumed to have more expertise than learner A.

Second, the task-selection process continues with the actual task selection by using the support and dif- ficulty level of the prior task and the self-assessment results and invested mental effort (i.e., expertise) for this task as a starting point. The expertise level of a learner indicates if he/she should select a new task with less, equal, or more support and of a lower, equal or higher difficulty level than the previous task. When the learner's expertise level is relatively high, he/she can select a task with less support and/or a task that is more difficult. Or, if the expertise level is relatively low, the learner should increase the support level and/or decrease the difficulty of the subsequent task. If the level of expertise is neither high nor low, the learner should select a task with equal support and similar difficulty. Returning to the example where learner $\mathrm{B}$ has more expertise than learner A, learner B should select a task with less support and/or a higher difficulty level than learner A.

Learners lacking necessary task-selection skills and domain knowledge might not understand the organization of the information presented in the tasks (Gay, 1986). They may not understand the difference between the different difficulty levels of the tasks and how they are organized in the environment. Thus, they will probably not choose appropriate tasks and, therefore, the selected tasks will not concur with their expertise. Consequently, choosing a learning pathway will be negatively affected with a concomitant hindrance in the acquisition of domain-specific skills. Learners who lack task-selection skills should be given advice to help them deal with the on-demand learning environment (Hannafin, 1984; Kalyuga, 2009; Kirschner, Sweller, \& Clark, 2006; Shin, Schallert, \& Savenye, 1994). This advice should provide the learner with information on what a suitable task would be by letting him/her focus on important task-selection aspects and by indicating a subset of tasks that best fits his/her expertise level. This subset decreases the breadth of available choices and helps learners focus on suitable tasks from which they can best make a selection.

\section{Design of an on-demand learning environment for simultaneous learning}

Thus far, it has been argued that an on-demand learning environment for novice learners should be designed according to a whole-task approach and should include relevant advice. The following sections explain how such an on-demand learning environment can be 
designed in a complex domain. The provided guidelines for designing such an environment are applicable in any domain, even when it is highly unstructured. The example for such an environment is set in the domain of system dynamics (i.e., a method to enhance learning about the behaviour of complex systems over time; Richardson \& Pugh, 1981). It simplifies complex dynamic systems by depicting them in models using flows and stocks and drawing graphs to show the behaviour over time of these flows and stocks.

The learning cycle (i.e., performing a task, assessing performance and selecting a next task) was followed in designing the environment. In this cycle, learners iteratively proceed through three steps. The number of iterations depends on the complexity of the domain, or, in other words, on how many tasks learners need to perform to master the domain-specific target skills and to transfer those skills to unfamiliar dynamic systems. In addition, learners must complete the cycle often enough to develop the SDL skills that enable them to choose an appropriate learning pathway. In this example, a system dynamics expert has indicated that nine tasks are needed to master the target system dynamics skills, which are all on a very basic level. Completing the learning cycle nine times should be sufficient to master the SDL skills at a basic level.

\section{Design of the learning tasks}

The learning tasks in this example are designed according to the whole-task approach where learners can acquire all important system dynamics skill components simultaneously in one task. More specifically, the four-component instructional design model (4C/ID model) (Van Merriënboer, 1997; Van Merriënboer \& Kirschner, 2013) was used to structure the environment. The 4C/ID model provides directives and suggestions for designing educational programs to acquire complex skills following the whole-task approach. It points out that to enable learners to gradually master domain-specific skills, task classes of increasing difficulty are defined. Here, tasks at different difficulty levels provide different solution strategies for solving system dynamics problems of different complexities. Working on tasks at higher difficulty levels helps learners become familiar with solution strategies for more complex situations, and, thus, to learn more about system dynamics.
The design of each task has the same structure regardless of difficulty level. The first assignment in each task is to read a case description and draw a system dynamics model that fits this description. Each case description is structured in the same way. An example of a case description is: 'Each hour 1000 cars drive on the highway and arrive at a cash toll gate with a cashier who takes the toll. 400 of these cars, with a chip for toll gates built in their car, decide to drive the car out of the queue in front of this cash toll gate and drive to a toll gate with an automatic scanner. From the eight hour onwards, more cars driving on the highway have the chip and use the automatic scanner, because at this time of the day the cars on the highway are business cars fitted with these chips. From then on, 600 cars per hour drive out of the queue to take the gate with the automatic scanner.' A system dynamics model must be drawn that fits this case description by using a legend with different system dynamics elements (see Figure 2). Learners can drag and drop elements into a grid to construct the model. They can attach a label to each element to explain what the element represents regarding the case description.

The second assignment in each learning task requests the learners to fill in a table about the behaviour of the elements of the model across time. The third assignment contains three multiple-choice questions requiring learners to choose, in order, the correct inflow/outflow graph, net flow graph, and stock graph which depict the behaviour of the inflow/outflow, net flow, and stock, respectively, over time according to the case description (note that for some case descriptions, there might be no stock and thus no stock graph). In addition, learners must explain why they selected a particular graph.

Although the learning tasks share the same structure, they differ in surface features which are task aspects not related to learning goals (Corbalan, Kester, \& Van Merriënboer, 2008). Moreover, they differ in difficulty level which means that they differ in system dynamics elements included in the case description and correct model of the task. Three difficulty levels are distinguished: easy, moderate and difficult. The cases in the different difficulty levels are designed on the basis of findings from studies conducted in system dynamics (Cronin \& Gonzalez, 2007; Cronin, Gonzalez, \& Sterman, 2009). These studies show that if a stock is included in a system with flows, then dealing with this 


\section{Legend System Dynamics Elements}

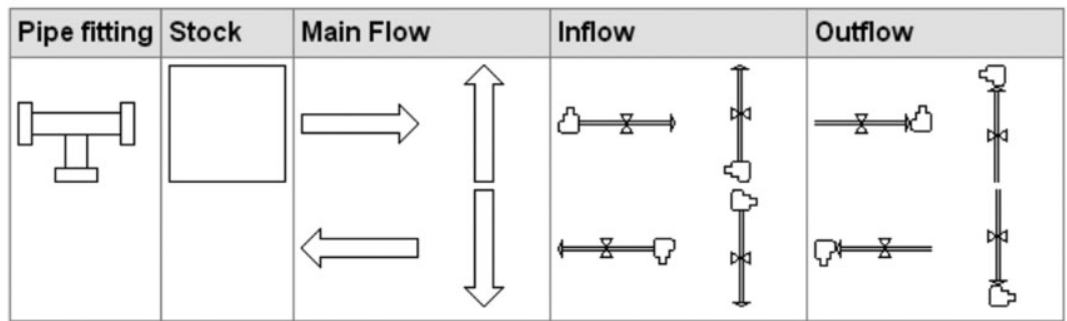

You can drag the elements of the legend to the cells and drop them in any cell you want. The cells can also be used for labelling by clicking on a cell, a pop-up appears to write in.

\section{Build the System Dynamics Model and label the elements}

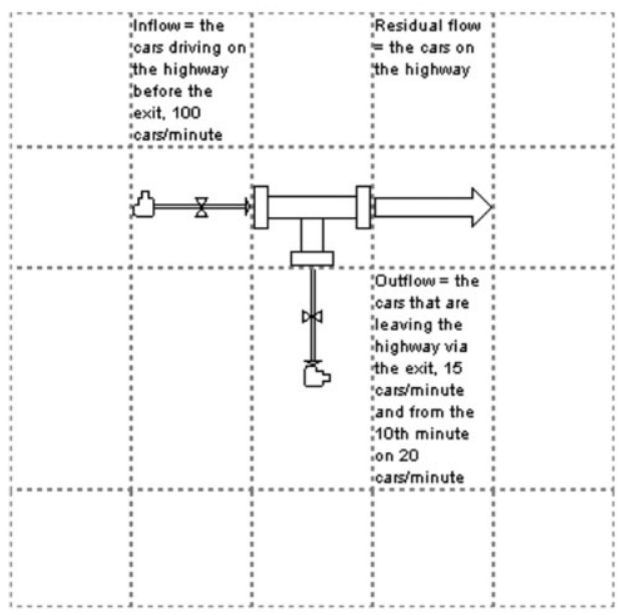

\section{Next $\gg$}

Figure 2 A Screenshot of the First Assignment of Each Learning Task, Showing the Legend (Top) and a System Dynamics Model Constructed by the Learner (Bottom)

system is unintuitive and difficult, even if it concerns simple systems, because the process of stock aсcumulation is influenced by the flow or flows going into or out of the stock over time. Therefore, a task fitting difficulty level 'easy' concerns a system and model with an inflow, an outflow and a residual flow (i.e., a net flow resulting from the amount of outflow subtracted from the amount of the inflow), but without a stock. A task of difficulty level 'moderate' has one inflow and a stock. The third difficulty level 'difficult' concerns a task with one inflow, a stock and one outflow. The 'moderate' and 'difficult' tasks that contain stock-flow problems are more difficult than the 'easy' tasks that contain only flow-flow problems. Furthermore, including an outflow (i.e., along with an inflow and a stock) in the 'difficult' tasks makes these tasks more difficult than 'moderate' tasks, which only contain an inflow and a stock. In the former, both inflow and outflow accumulate in and out of the stock over time, while in the latter only inflow accumulates in the stock over time.

An example of a case description of a task with difficulty level 'easy' is the case description of the cars arriving at the toll gates which was provided earlier. In this case, the cars arriving at the cash toll gate and forming the queue are the inflow, those leaving this queue to drive to the toll gate with an automatic scanner are the outflow, and those remaining in the queue and arriving at the cash toll gate are the residual flow. The model fitting this difficulty level is depicted in Figure 3a. The elements have to be connected by a pipe fitting, which is an element especially designed for 

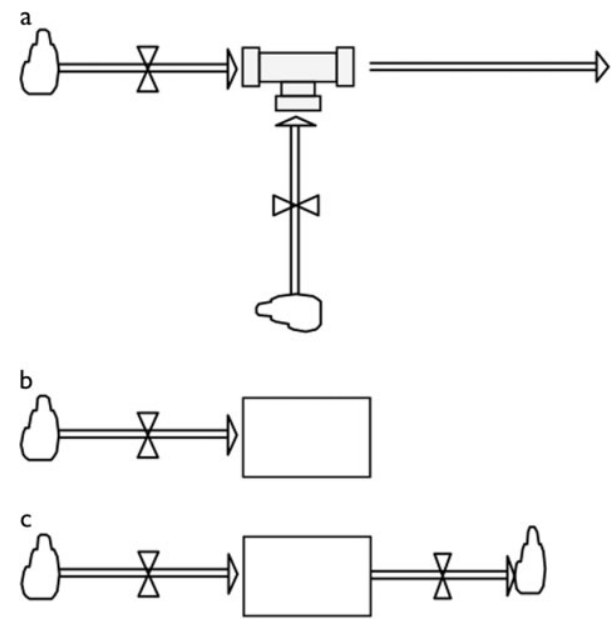

Figure 3 Models Resulting From the Case Descriptions of the Three Different Difficulty Levels (a) 'easy', (b) 'moderate' and (c) 'difficult'. (a) Model for Difficulty Level 'easy' With From Top Left to Top Right an Inflow, a Pipe Fitting, and a Residual Flow, and Below the Pipe Fitting an Outflow. (b) Model for Difficulty Level 'moderate' With From Left to Right an Inflow and a Stock. (c) Model for Difficulty Level 'difficult' With From Left to Right an Inflow, a Stock and an Outflow

cases that do not contain one or more stocks for the flows to be connected to each other.

An example of a case description that fits a task of difficulty level 'moderate' is: 'Maria has 1000 Euros in her savings account when she set up this account. She adds 200 Euros to it each month. From the third month on, her income increases and she begins to put 400 Euros each month into her savings account.' In this case, the money Maria saves each month is the inflow, her savings account is the stock, and there is no outflow. The model that fits this difficulty level is depicted in Figure 3b.

Finally, an example of a case description of a task with difficulty level 'difficult' is: 'Brian starts working on a farm picking apples. The farmer gives him a large box that already has 10 apples in it. Every minute Brian picks 10 apples and puts them in the box. The farmer continually checks the box and takes out the bad apples. The farmer takes out 5 bad apples each minute that Brian picks. He tells Brian he needs to look better to see if he is not picking bad apples. From the fourth minute onwards, the farmer only has to take out 2 bad apples each minute.' In this case, the number of apples Brian picks each minute is the inflow, the stock is the total number of apples he has in his box, and the outflow is the number of apples the farmer takes out of the box each minute. The model that fits this difficulty level is depicted in Figure 3c.

Tasks also differ in the level of support they provide. Giving more or less solution steps enables scaffolding (i.e., diminishing support; the scaffolding principle as specified in the 4C/ID model; Van Merriënboer, 1997; Van Merriënboer \& Kirschner, 2013) as learners develop their domain-specific skills while performing tasks of one difficulty level. Each difficulty level contains support at the same three levels: 'high', 'medium' and 'low'. Tasks at different support levels provide different numbers of solution steps for the system dynamics problem under consideration. A task with 'high' support is a worked-out example where all solution steps and correct answers are given and learners are instructed to study this example. A task with 'medium' support is a completion task with some solution steps including correct answers provided and other solution steps with the correct answers not provided. Thus, the learners have to fill in the missing solution steps and/or answers. A task of support level 'low' is a conventional task in which a given state is described, but no solution steps or correct answers are given. The learners have to solve all steps by themselves. Still, in the first assignment, some support is provided by giving the learners the legend with system dynamics elements to build the model with, and in the third assignment, multiple-choice questions are provided that each contains four options from which to choose the correct graph.

All these different learning tasks enable the learners to meet their individual learning needs and acquire all necessary components of the system dynamics skills. The learning needs are determined by assessing the learner's performance on the prior task. A learner should use the self-assessment results to know what his/her learning needs are and to select new tasks that best help improve performance. Therefore, after each task the learning cycle continues with the learner selfassessing his/her performance on the learning task to accurately identify his/her learning needs.

\section{Design of the self-assessment advice}

Learners are presented with their answers to the justcompleted task so that they can compare them to the correct answers that are also available. Note that the advice does not provide feedback to the learners, 
neither for correct answers nor for incorrect answers. This requires learners to consciously compare their own answers with the given answers, and it prevents them from focusing on the incorrect answers when assessing their performance. Thus, the comparison is the sole basis for the self-assessment. Learners are given self-assessment advice to help them with their self-assessment. This advice is based on the theory for advisement described by Kicken, Brand-Gruwel, and Van Merriënboer (2008) and consists of a scoring rubric with relevant performance standards and a rating scale (i.e., $1=$ bad to $5=$ good) (see Table 1 ).

Each performance standard is derived from one of the solution steps in the performed task. Learners are instructed to assess their performance on a number of task-relevant standards using the rating scale after having carried out a completion task or conventional task, and to assess their understanding on a number of task-relevant standards using the rating scale when they studied a worked-out example.

The scoring rubric informs learners as to which standards for good performance they should take into account while assessing their performance. The rubric contains all standards for performing a whole learning task. The scoring rubric in Table 1 contains all performance standards for tasks with a difficulty level of 'difficult'. The number of standards decreases somewhat when the system dynamics system does not include an outflow, as in tasks with a 'moderate' difficulty level, or does not include a stock, as in tasks with an 'easy' difficulty level, because the performance standards for these elements are not applicable there. Learners must assess their performance on each standard in the rubric using the rating scale. The advice might make clear how they should assess performance and what performance standards to use. Providing all the relevant standards to the learners prevents them from assessing their performance on too little relevant standards or on irrelevant standards. Hence, this selfassessment advice might help them to know if they have considerably improved performance, and, therefore, it might prevent them from overestimating or underestimating the quality of their performance and eliminate learner misconceptions as to what is expected from them. In addition, the advice might help them identify suitable learning needs. After the selfassessment, learners continue by selecting an appropriate subsequent task.

Table 1. Scoring Rubric With Task-Relevant Performance Standards

\begin{tabular}{|c|c|c|c|c|c|c|}
\hline & & \multicolumn{5}{|c|}{ Rating scale } \\
\hline \multicolumn{2}{|c|}{ Task-relevant standards } & Bad & Poor & Neutral & Satisfactory & Good \\
\hline \multirow[t]{4}{*}{ Model } & Identifying all flows and the stock & o & o & o & o & o \\
\hline & Constructing the model & o & o & 0 & o & o \\
\hline & Labelling the elements & o & o & o & o & o \\
\hline & $\begin{array}{l}\text { Labelling the amount of flow(s) and } \\
\text { stock including the change in flow }\end{array}$ & o & o & o & o & o \\
\hline \multirow[t]{3}{*}{ Table } & $\begin{array}{l}\text { Filling in the amount of inflow (and } \\
\text { outflow) in the table }\end{array}$ & o & o & o & o & o \\
\hline & Filling in the net flow in the table & o & o & 0 & o & o \\
\hline & Filling in the stock in the table & o & 0 & 0 & 0 & 0 \\
\hline \multirow[t]{6}{*}{ Graphs } & $\begin{array}{l}\text { Predicting the correct inflow and } \\
\text { outflow graph }\end{array}$ & o & o & o & o & o \\
\hline & $\begin{array}{l}\text { Interpreting why the inflow and outflow } \\
\text { graph is the correct graph }\end{array}$ & o & o & o & o & o \\
\hline & Predicting the correct net flow graph & o & o & 0 & 0 & o \\
\hline & $\begin{array}{l}\text { Interpreting why the net flow graph is } \\
\text { the correct graph }\end{array}$ & o & o & o & o & o \\
\hline & Predicting the correct stock graph & o & o & 0 & 0 & o \\
\hline & $\begin{array}{l}\text { Interpreting why the stock graph is the } \\
\text { correct graph }\end{array}$ & o & o & o & o & o \\
\hline \multirow[t]{2}{*}{ Task in total } & Time on performing the task & o & o & 0 & 0 & o \\
\hline & Understanding the whole task & o & o & 0 & 0 & 0 \\
\hline
\end{tabular}




\section{Design of the task-selection advice}

The task database in an on-demand learning environment can contain a large number of tasks to choose from, which can be overwhelming for novices in a domain (Corbalan et al., 2006). While choosing from a small number of tasks (e.g., six tasks) seems to increase intrinsic motivation which enhances performance (Iyengar \& Lepper, 2000), choosing out of a large number of tasks (e.g., 24 tasks or more) might not have such benefits. Learners who lack task-selection skills and, thus, do not know on which task aspects to focus on while selecting a task can find such a large number difficult to manage and can get easily overloaded (Corbalan et al., 2006; Iyengar \& Lepper, 2000). They might even become demotivated to continue searching for the best tasks and learning might be hampered (Iyengar \& Lepper, 2000; Katz \& Assor, 2007). It may also lead to low perceived self-efficacy and the selection of tasks that are too easy and do not fit their expertise level (Bandura, 1994).
A study of Bell and Kozlowski (2002) shows a possible solution for these problems. They designed an on-demand environment that provided adaptive guidance in the form of a task database with different learning topics structured in a ramped sequence. Based on learner's performance, advice on what their learning needs are and what kind of aspects of the tasks to practice and study was provided. This environment with the advice and structured task database had a positive effect on setting appropriate learning trajectories and gaining strategic domain knowledge.

Therefore, the on-demand learning environment contains a structured task database including all learning tasks in system dynamics varying in difficulty level and support level (see the table in Figure 4). Learners select learning tasks from this task database which are structured from simple tasks (i.e., tasks with difficulty level 'easy' and support level 'high') to harder tasks (i.e., tasks with difficulty level ' difficult' and support level 'low') to help them select tasks at an appropriate difficulty level and with the appropriate amount of

\section{Task selection}

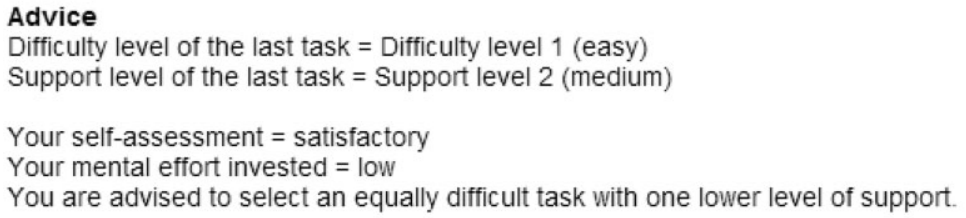

\begin{tabular}{|l|l|l|l|l|l|l|l|l|l|}
\hline Difficulty level & \multicolumn{3}{l}{ Easy } & \multicolumn{3}{l|l}{ Moderate } & \multicolumn{2}{l|}{ Difficult } \\
\hline Support level & High & Medium & Low & High & Medium & Low & High & Medium & Low \\
\hline & 0 & 0 & 0 & 0 & 0 & 0 & 0 & 0 & 0 \\
& 2 & 0 & 0 & 0 & 0 & 0 & 0 & 0 & 0 \\
& 0 & 0 & 0 & 0 & 0 & 0 & 0 & 0 & 0 \\
Tasks with a & 0 & 0 & 0 & 0 & 0 & 0 & 0 & 0 & 0 \\
different & 3 & 4 & 0 & 0 & 0 & 0 & 0 & 0 & 0 \\
coverstory & 0 & 0 & 0 & 0 & 0 & 0 & 0 & 0 & 0 \\
& 0 & 0 & 0 & 0 & 0 & 0 & 0 & 0 & 0 \\
& 1 & 0 & 0 & 0 & 0 & 0 & 0 & 0 & 0 \\
& 0 & 0 & 0 & 0 & 0 & 0 & 0 & 0 & 0 \\
\hline
\end{tabular}

The numbers indicate the sequence in which you have selected the tasks.

Figure 4 Screenshot of the TaskSelection Screen in the Learning Cycle of an On-Demand Learning Environment With Advice on Task Selection
Click on a radio button to see the description of a task

Next $>>$ 
support. The tasks are depicted as radio buttons. Within each combination of difficulty and support level, nine tasks are included which vary in their case descriptions (i.e., surface features). This enables learners to select a task of the same difficulty and support level nine times in a row if necessary.

Before a learner actually selects a task from this task database, he/she can scroll over a radio button to let a pop-up appear with the title of the task. If the learner clicks on a button, he/she can read the whole case description before actually selecting the task. Some radio buttons in the task database are replaced by numbers to show which tasks the learner has already performed and in what order. Thus, the learner can monitor his/her own learning path. The learner is free in selecting any task he/she wants to select, even if he/she wants to select a task of the same complexity level a couple of times, except of course for the tasks already performed.

The nine learning tasks for each of the nine combinations of difficulty level and support level result in a task database containing 81 learning tasks. This is a large number of tasks which makes it difficult for learners without task-selection skills to select an appropriate task. Therefore, before actually selecting a task, learners receive advice on task selection. Bell and Kozlowski (2002) provided advice on what task aspects need to be practised and studied. This advice was based on the performance of the learners. Such advice might prevent the novices to learn to focus on their self-assessment when having to select a task. Therefore, in the on-demand environment that is presented here, the advice is based on learners' selfassessment to show them how to select a next task using their self-assessment.

Although the self-assessment advice might help the learners to see what their learning needs are, they should also be advised on what task-selection aspects to take into account for selecting a task and what tasks with what particular task aspects suit their learning needs. Therefore, the task-selection advice provides a list of relevant task-selection aspects to take into account for selecting a next task (i.e., difficulty and support level of the last performed task, selfassessment score, and mental effort score; see the top of Figure 4). The mental effort is a relevant taskselection aspect too, because the combination of selfassessment and mental effort is a useful indicator of good task selection (Van Merriënboer et al., 2006). This self-assessment score is calculated by taking the mean of all self-assessments on all performance standards in the self-assessment rubric. The weight of each self-assessment is the same; however, the number of standards for each task assignment varies according to the number of solution steps in an assignment. Therefore, the weight of an assignment depends on the number of its solution steps, and, thus, on its complexity. To obtain a mental effort score, the mental effort question is presented to the learner immediately after performing a task. The mental effort is indicated by the learner on a 5-point rating scale, just as the selfassessment rating scale, however, now ranging from 1 (very low) to 5 (very high) (Paas et al., 2003). Providing the list of relevant task-selection aspects might help learners focus on these aspects.

Moreover, additional task-selection advice provides a straightforward recommendation on the best level of difficulty and support for the next task. The selfassessment scores and mental effort scores are used in a task-selection algorithm (see Table 2). For this algorithm, it is necessary to provide a mental effort scale that can be linked to the self-assessment scale; therefore, the mental effort rating scale should have the same range as the self-assessment scale. This algorithm contains rules that are used to present specific advice for each combination of self-assessment and mental effort scores. The rules are based on the algorithm for a system-controlled environment of Salden et al. (2004) in which a system selected the tasks for the learners based on both performance score and mental effort score. In the current environment, the learners have full control and, therefore, they should learn that a particular task is advised because it corresponds to

Table 2. Table With the Algorithm Rules for Providing Task-Selection Advice, With the Self-Assessment Rating Scale From 1 'Bad' to 5 'Good', and the Mental- Effort Rating Scale From 1 'Very Low' to 5 'Very High'

\begin{tabular}{lrrrrr}
\hline \multicolumn{5}{c}{ Self-assessment } \\
$\begin{array}{l}\text { Mental } \\
\text { effort }\end{array}$ & 1 & 2 & 3 & 4 & 5 \\
\cline { 2 - 6 } & 0 & +1 & +2 & +3 & +4 \\
1 & -1 & 0 & +1 & +2 & +3 \\
2 & -2 & -1 & 0 & +1 & +2 \\
3 & -3 & -2 & -1 & 0 & +1 \\
4 & -4 & -3 & -2 & -1 & 0 \\
5 & & & & & \\
\hline
\end{tabular}


their self-assessment and not to their performance assessed by the system. Under these conditions, the learners can learn how to use their self-assessment to select a suitable task in order to handle on-demand environments that do not contain advice. Hence, the performance scores in the algorithm rules are replaced with the self-assessment scores.

Each combination of self-assessment and mental effort scores leads to a step size used to indicate the difficulty level and support level for the subsequent task that is advised. To use the step size, one must imagine that each combination of difficulty level and support level is ordered in columns in the task database from simple tasks to hard tasks. Each combination can be numbered from 1 for 'easy' tasks with 'high' support (left hand column of the task database) to 9 for 'difficult' tasks with 'low' support (right hand column of the task database).

The step size indicates the number of steps added to or subtracted from a combination of difficulty and support level of the previously performed task, depending on the step size being positive or negative, respectively. This leads to the difficulty and support level of the next task to be advised. For example, a learner who just performed a 'moderate' task with 'high' support has assessed his/her performance with a mean score of 'good' (i.e., 5) with a mental effort score of 'neither low nor high' (i.e., 3). Following the rules of the algorithm in Table 2, this self-assessment and mental effort lead to a step size of 2 . This step size is added to the combination 4 of the difficulty and support level of the prior task, resulting in the advice to select a task of 'moderate' difficulty with 'low' support (i.e., combination 6) as suitable.

The difficulty and support levels indicated by the algorithm are automatically transformed into a recommendation that directly specifies what difficulty and support level are indicated by the step size. The recommendation is constructed using a general proposition containing all options on difficulty and support levels: 'You are advised to select a task which is two levels less/one level less/ equally/one level more/two levels more difficult with two levels higher/one level higher/ equal/one level lower/two levels lower support.' The recommendation that would fit the previous example would be: 'You are advised to select an equally difficult task with two levels lower support.' In addition, the column in the task database with the subset of appro- priate tasks as indicated by the recommendation is given a colour to aid learners in translating the textual advice to actually selecting a task. This part of the task-selection advice might prevent learners from becoming overloaded by the large number of tasks in the task database, because the choice is reduced to a subset of appropriate tasks to choose from. It should be noted that at the start of the first learning cycle, all learners are advised to select a task of difficulty level 'easy' and support level 'high'. This task is a workedout example of an easy task, and, thus, a suitable task to learn how a simple system dynamics task can be solved. It helps learners to get acquainted with the solution steps in the learning tasks of difficulty level 'easy'.

The 4C/ID model points out that it is important for learners to first test whether they can successfully perform a conventional task on one difficulty level before continuing to the next difficulty level (Van Merriënboer, 1997; Van Merriënboer \& Kirschner, 2013). Conventional tasks are tasks closest to real-life tasks (i.e., they contain no support or guidance). Only when such a task is carried out successfully can one conclude that the learner has acquired the system dynamics skills sufficiently to perform similar tasks at the same difficulty level and is able to transfer these skills to unfamiliar real-life tasks of similar difficulty. This enables the learners to complete the learning cycle and select a task with a higher difficulty level which restarts the learning cycle at a higher system dynamics skill level. Therefore, an additional rule is implemented in the algorithm which advises against proceeding to the next difficulty level before having successfully performed at least one conventional task at the current difficulty level (i.e., the advice will be to perform tasks of the same difficulty level and with low support).

To sum up, learners start by selecting their first task at difficulty level 'easy' and support level 'high'. They perform this task, can get acquainted with the learning environment and the domain of system dynamics, and assess their first task performance. Next, they select a task based on the advice that might help them take their self-assessed learning needs and mental effort into account to improve performance. The learners carry out the selected task and assess their performance again. They can check whether they satisfied their learning needs and improved their domain-specific skills. Furthermore, their self-assessment and mental 
effort can be taken into account when they select a subsequent task. Performing this task can, again, enable them to work on their points of improvement and learning might be further increased. This shows that acquiring both system dynamics skills and SDL skills is interwoven in this environment and may enable learners to acquire them simultaneously. The learning cycle is iterated nine times, so that eventually learners have carried out nine learning tasks, assessed their performance nine times and selected nine tasks.

\section{What learners do with the advice}

Learners might not perceive the advice as intended by its designers. If this occurs, learners probably will not use the advice as it is meant to be used (Könings, Brand-Gruwel, \& Van Merriënboer, 2011; Vandewaetere, Vandercruysse, \& Clarebout, 2011). Hence, their learning outcomes can be negatively affected. Therefore, as a first step, data with regard to the learners' perceptions of the advice should be gathered in order to see if they are in accordance with those of the designers. The differences in perceived usefulness and appropriateness of the advice by the learners and the designers can, in turn, be used to improve the advice given in the learning environment. Therefore, in the following two short studies, learners were asked to evaluate the advice. They were working in a Web-based on-demand learning environment designed following the recommendations of this paper. After working in this environment, they had to evaluate the advice by answering a questionnaire on paper and a questionnaire built in the same Web-based environment. Each questionnaire included open questions set up for the specific study; the Web-based questionnaire included empty text boxes for each answer. In both studies, the questionnaires were provided directly after participants finished working in the learning environment. All participants were prevented from knowing how other participants evaluated the learning environment.

In a first pilot study, 5 students ( 1 female and 4 male, mean age $=21.40$ years; $S D=1.82 ; 4$ studying International Business and Economics and 1 studying Arts and Social Sciences at a Dutch university) worked in the learning environment and were questioned on their perceptions on the advice on self-assessment. They were asked whether they: liked the advice, understood how to use the scoring rubric, missed certain performance standards, and liked using such a scoring rubric. The answers show that most of them liked the advice, except for one student who remarked that he was guided in the environment (i.e., he felt that '... It is going to be guided anyway.'). All students understood how to use the scoring rubric and did not miss any performance standards in the rubric. All students liked using the rubric except for one student who did not like the system because he felt too much guided by the task-selection advice.

The on-demand learning environment on system dynamics with advice on self-assessment and task selection was again provided to 17 students ( 12 female and 5 male, mean age $=20.47$ years; $S D=1.55 ; 16$ studying International Business and Economics at two Dutch universities, and 1 studying Humanities and Social Sciences at a Dutch university). Next to gathering the logged data whether students' task selections were in accordance with the task-selection advice, these students were questioned about their perceptions on the task-selection advice. They completed a course of study according to the cyclical learning model for nine iterations. At the end of this study, they received the questionnaire in which it was indicated what the advice was after each task performance, which tasks they selected, and, thus, whether or not they followed the advice. For each task selection, they were asked why they had or had not followed the advice and they had to provide at least one justification. The text box triggered them to write down why they did or did not follow the task-selection advice and if they thought the advice was appropriate or not.

The responses to this questionnaire show that a majority of $78 \%$ of the students' task selections were tasks that belonged to the subset indicated by the taskselection advice. All reasons provided by students for following the advice are shown in Table 3, including the percentage of each reason relative to the total number of reasons given for following the advice.

In general, the results show that students have a positive attitude towards the advice. They find the advice logical, sensible and good. They think that it helps them increase their knowledge and fits their idea of selecting a suitable task. Moreover, when they start their learning pathways, they indicate that they do not know what to expect and think the advice is useful at the beginning of the pathway. However, in $17 \%$ of the 
Table 3. Overview of the Perceptions of the Learners on the Task-Selection Advice

Following the advice (78\%)

Percentage relative

Logical, sensible, and good advice

to total provided reasons

In accordance to learner's urge to increase knowledge

31.0

Advice was straightforward and just followed it

23.0

Unconfident about performance on the prior task

17.0

15.0

No idea how to handle the environment when starting to work in the learning cycle

Advice was challenging

9.0

4.0

To try the advise

1.0

Not following the advice (22\%)

Reason

Percentage of total

provided reasons

Advice was inappropriate

70.3

Did not agree with the advice

26.9

Wanted to select a less complex task than the advised tasks

26.9

Learned enough and wanted to run faster through the cycle by selecting a task

of support level high

Wanted to restudy another task than the advised task

11.5

Did not want to perform the same kind of tasks over and over $\quad 11.5$

Wanted to select a more complex task than the advised tasks

Not concentrated and did not notice the advice

7.7

Advice was misunderstood

cases, they followed the advice because it was straightforwardly telling them which task to select.

However, in $22 \%$ of the cases, the task selected was not a task that was advised. The reasons provided as to why the advice was not followed are provided in Table 3, including the percentage of each reason relative to the total number of reasons given for not following the advice. It turns out that in $70 \%$ of the cases where the advice was not followed, students thought the advice was not appropriate. Thus, in $15.4 \%$ of all cases ( $70 \%$ of $22 \%$ ), the given advice was not followed because it was considered not appropriate. It is interesting to note that these students more often felt this way because they wanted to select a task that was less complex than the advised task (27\% of $70 \%)$ than a task that was more complex than the advised task ( $8 \%$ of $70 \%)$. However, in $27 \%$ of the times, the students did not follow the advice because they were not concentrated.

\section{Discussion}

Testing student's perception of the advice on selfassessment and task selection did show that in some cases the learners' perceptions corresponded to those of the designers, but in other cases they did not. The differences between learners and designers' perceptions need to be decreased because only when they correspond that it is likely the desired learning outcomes will be met (Könings et al., 2011; Vandewaetere \& Clarebout, 2011; Vandewaetere et al., 2011).

The pilot study showed that the advice provided the expected performance standards and most of the students appreciated it. Only one student felt the scoring rubric was unnecessary because the task-selection advice, in his eyes, made the self-assessment advice superfluous. This particular student was probably unaware of the fact that the task-selection advice was based on his own self-assessment. To improve the environment, this misconception needs to be dealt with. A learner should be aware of the importance of correctly self-assessing his/her performance by filling in the scoring rubric. Therefore, more information should be provided that the scoring rubric helps him/ her self-assess appropriately and that the selfassessment results are used as an input for advice on task selection. 
In general, students followed the advice when selecting a new task and indicated that they felt the advice was appropriate (i.e., logical, sensible and good advice). They expected that performing the advised task would improve their knowledge. Moreover, they indicated to follow the advice when they were unconfident about their prior task performance, when they expected that it would lead them to challenging tasks that will increase their learning, or when they wanted to try the advice to get acquainted with it. Furthermore, the advice was seen as useful when starting their learning pathways because it helped them deal with the unfamiliar environment. This indicates how important it is to implement advice in an on-demand learning environment.

However, some students indicated that they 'just followed the advice' without thinking about why they should follow it. They did not consciously consider the selection of a suitable task, which might have hampered their development of task -selection skills. Therefore, it might be necessary to trigger learners to explicitly consider why they should or should not follow the advice. For example, it could include an additional explanation why a task is advised or learners could be asked when the task-selection advice is provided to indicate why the subset of advised tasks is appropriate to choose a task from. Thus, advice should also stimulate learners to think about the selection process.

Students also selected tasks that were not in the advised subset of tasks. The main reason given for this was that they perceived the advice as inappropriate. To get learners to follow the advice, the above-mentioned elaborated explanation of why the subset of tasks is advised should help. This will prevent learners from immediately discarding the advice as inappropriate (i.e., 'Did not agree with the advice'). Moreover, making it more explicit that the advice given to them is based on their own self-assessment and mental effort scores and is thus different for each individual, learner should help too. In other words, this improvement would help learners realize that the advised tasks are suitable for them, even when they are simpler or harder than the task that they themselves see as appropriate. This might also be true for advice indicating performance of a similar task (i.e., same difficulty, same support level), because studying similar tasks with different case descriptions helps them transfer their knowledge to unfamiliar situations. Finally, more elaborate explanations can discourage learners from predominantly choosing tasks with high support so as to go through the learning cycle more quickly. Such additional explanations might help learners better understand why it is best for them to follow the given advice.

Another reason for not following the advice (in 27\% of the cases) was that students were not concentrated, did not notice the advice or simply forgot to follow it. Salience is, thus, a prerequisite. Straightforward recommendations can be highlighted or depicted in a pop-up in the task database. When they have read the advice, they can then close the pop-up and select the next task. These changes in the environment, however, need to trigger learners to think about why a task is advised and not just slavishly follow the advice. All these suggestions, in order to clarify the advice, might also prevent the learners from misunderstanding the advice.

After following these suggestions to improve the learning environment, future research should be conducted to test if this learning environment with the advice on self-assessment and task selection has the desired learning outcomes, namely the acquisition of domain-specific skills and SDL skills.

An on-demand learning environment such as the one described in this article can be used for learners of all ages. A prerequisite is that the learner must be old enough to deal with the control and responsibility the environment gives them. A second consideration is that the model employed here is designed to be used in on-demand education where learners have limited SDL skills. If a learner's SDL skills are well developed, such a model might lead to an expertise reversal effect (cf. Kalyuga, Ayres, Chandler, \& Sweller, 2003). Learners who already have well-developed SDL skills may be hampered by the advice on how to self-assess their performance and on how to select suitable tasks. To remedy this, the advice should be scaffolded (i.e., gradually faded) appropriately (Collins, Brown, \& Newman, 1987; Van Merriënboer \& Kirschner, 2013), first providing complete advice and then decreasing it as learners acquire or exhibit necessary SDL skills.

This principle of second-order scaffolding is similar to traditional first-order scaffolding of domain-specific skills from high support (e.g., worked-out examples) to low support (e.g., conventional tasks). Second-order scaffolding can be achieved, for example, by first asking learners to assess their performance for a given list of standards and then asking them to assess their performance in a scoring rubric without given standards. The 
advice on task selection can also be decreased by not providing specific recommendations, but rather by only providing relevant task-selection aspects. In time, when learners can assess their own performance and select suitable tasks without support, the advice can be eliminated. At this point, learners have become self-directed capable of optimally using the on-demand learning environment without any advice.

The advice in our on-demand learning environment mainly focused on particular aspects of SDL skills, namely self-assessment and task-selection skills. However, future research might also test whether advice in such an environment can help improve selfregulated learning aspects such as motivation and goal setting and study if it helps learners increase their learning outcomes (Winters, Greene, \& Costich, 2008).

\section{Conclusion}

On-demand education can be beneficial for learning if learners have the SDL skills necessary for dealing with this type of education. Learners follow the learning cycle of task performance, performance assessment and task selection iteratively, whereby the acquisition of both domain skills and SDL skills is interrelated and inseparable. When learners are novices in a domain, a lack of SDL skills makes it especially difficult for them to determine an appropriate learning pathway. Consequently, their pathways will not be optimally adapted to their low expertise level leading to negative effects on the development of domain-specific skills. To remedy this, SDL skills need to be developed in conjunction with domain-specific skills. A whole-task approach in which the learner receives guidance on his/her performance as well as advice on both self-assessment and task selection might be an appropriate basis for designing an on-demand learning environment where learners have the opportunity to develop two types of complex skills simultaneously.

This article discussed the design of such an on-demand, whole-task learning environment, in which domain-specific and SDL skills might simultaneously be developed. The 4C/ID model was used as a starting point. All learning tasks contain all components of the domain skills, differing in both difficulty levels and support levels. This enabled learners to start with a simple task and continue with tasks that gradually become more difficult while improving their domain- specific skills. To optimally improve their skills, the learners need to take their learning needs into account when performing each task. In this way, learners can develop all skill components right from the start and gradually increase the quality of their domain skills.

Learners receive advice on self-assessment when they assess their own task performance, which might aid them by a scoring rubric with performance standards for rating their performance so that they know what the standards are and might better rate their performance (i.e., avoiding underestimation or overestimation). They can then use this self-assessment to select a subsequent task. To help learners accurately select a task, they receive advice that could draw their attention to relevant task-selection aspects and shows which tasks suit those aspects. After this, a suitable task might be selected. Carrying out this task enables them to work on their points of improvement and increase the quality of their domain-specific skills.

Learners' perceptions of the advice on selfassessment and advice on task selection were studied to investigate if the advice was perceived as intended. In general, the learners indicated that the advice was appropriate. The majority of the learners pointed out that they liked to use the advice on self-assessment, and understood how to use it, and most students followed the advice on task selection because they perceived it as logical, sensible and good. However, some students indicated that they 'just followed the TS (taskselection) advice' without giving it a second thought. The few students who did not follow the TS (taskselection) advice pointed out that they perceived this advice as inappropriate, were not concentrated, did not notice the advice or simply forgot to follow it. Suggestions are provided to improve the advice and meet the desired outcomes of this on-demand learning environment. The main suggestion is to provide information why the advice is important to take into account and trigger learners to consider why they should use it. Moreover, it should inform them on what aspects the advice is based and it should be saliently depicted.

Future research should be conducted to test the effects of this environment on the acquisition of domain-specific skills and SDL skills. Prerequisites for future research are provided concerning the age and expertise level of the learners. Learners should be old enough and should be novices in both the domain and the SDL. When learners have already developed 
(some) SDL skills, it is recommended to use the principle of second-order scaffolding to prevent an expertise reversal effect.

\section{References}

Bandura, A. (1994). Self-efficacy. In V. S. Ramachaudran (Ed.), Encyclopedia of human behaviour (Vol. 4, pp. 721781). New York, NY: Academic Press.

Bell, B. S., \& Kozlowski, S. W. J. (2002). Adaptive guidance: Enhancing self-regulation, knowledge, and performance in technology-based training. Personnel Psychology, 55, 267-306. doi:10.1111/j.1744-6570.2002.tb00111.x

Bjork, R. A. (1999). Assessing our own competence: Heuristics and illusions. In D. Gopher \& A. Koriat (Eds.), Attention and performance XVII - cognitive regulation of performance: Interaction of theory and application (pp. 435-459). Cambridge, MA: MIT Press.

Brand-Gruwel, S., Kester, L., Kicken, W., \& Kirsches, P. A. (2014). Learning ability development in flexible learning environments. In J. M. Spector, D. M. Merrill, J. Elen, \& M. J. Bishop (Eds.), Handbook of research on educational communications and technology (pp. 363-372). New York, NY: Springer.

Camp, G., Paas, F., Rikers, R., \& Van Merriënboer, J. J. G. (2001). Dynamic problem selection in air traffic control training: A comparison between performance, mental effort and mental efficiency. Computers in Human Behavior, 17, 575-595.

Clark, R. C., \& Mayer, R. E. (2008). E-learning and the science of instruction (2nd ed.). San Francisco, CA: Jossey-Bass/Pfeiffer.

Collins, A., Brown, J. S., \& Newman, S. E. (1987). Cognitive apprenticeship: Teaching the craft of reading, writing and mathematics (Technical Report No. 403). BBN Laboratories, Cambridge, MA. Centre for the Study of Reading, University of Illinois. January 1987.

Corbalan, G., Kester, L., \& Van Merriënboer, J. J. G. (2006). Towards a personalized task selection model with shared instructional control. Instructional Science, 34, 399-422.

Corbalan, G., Kester, L., \& Van Merriënboer, J. J. G. (2008). Selecting learning tasks: Effects of adaptation and shared control on efficiency and task involvement. Contemporary Educational Psychology, 33, 733-756.

Cronin, M. A., \& Gonzalez, C. (2007). Understanding the building blocks of dynamic systems. System Dynamics Review, 23(1), 1-17.

Cronin, M. A., Gonzalez, C., \& Sterman, J. D. (2009). Why don't well-educated adults understand accumulation? A challenge to researchers, educators, and citizens.
Organizational Behavior and Human Decision Processes, 108, 116-130.

Ellinger, A. D. (2004). The concept of self-directed learning and its implications for human resource development. Advances in Developing Human Resources, 6, 158-177.

Gay, G. (1986). Interaction of learner control and prior understanding in computer-assisted video instruction. Journal of Educational Psychology, 78, 225-227.

Gerjets, P., Scheiter, K., Opfermann, M., Hesse, F. W., \& Eysink, T. H. S. (2009). Learning in hypermedia: The influence of representational formats and different levels of learner control on performance and learning behavior. Computers in Human Behavior, 25, 360-370.

Hannafin, M. J. (1984). Guidelines for using locus of instructional control in the design of computer-assisted instruction. Journal of Instructional Development, 7(3), 6-10.

Iyengar, S. S., \& Lepper, M. R. (2000). When choice is demotivating: Can one desire too much of a good thing? Journal of Personality and Social Psychology, 79(6), 9951006. doi:10.1037//0022-3514.79.6.995

Kalyuga, S. (2009). Instructional designs for the development of transferable knowledge and skills: A cognitive load perspective. Computers in Human Behavior, 24, 332-338. doi:10.1016/j.chb.2008.12019

Kalyuga, S., Ayres, P., Chandler, P., \& Sweller, J. (2003). The expertise reversal effect. Educational Psychologist, 38(1), 23-31.

Katz, I., \& Assor, A. (2007). When choice motivates and when it does not. Educational Psychology Review, 19, 429-442. doi:10.1007/s10648-006-9027-y

Kicken, W., Brand-Gruwel, S., \& Van Merriënboer, J. J. G. (2008). Scaffolding advice on task selection: A safe path toward self-directed learning in on-demand education. Journal of Vocational Education and Training, 60, 223239.

Kicken, W., Brand-Gruwel, S., Van Merriënboer, J. J. G., \& Slot, W. (2009). The effects of portfolio-based advice on the development of self-directed learning skills in secondary vocational education. Educational Technology Research and Development: ETR \& D, 57(4), 439-460.

Kinzie, M. B., \& Sullivan, H. J. (1989). Continuing motivation, learner control, and CAI. Educational Technology Research and Development: ETR \& D, 37(2), 5-14.

Kirschner, P. A., Sweller, J., \& Clark, R. E. (2006). Why minimal guidance during instruction does not work: An analysis of the failure of constructivist, discovery, problem-based, experiential, and inquiry-based teaching. Educational Psychologist, 41(2), 75-86.

Könings, K. D., Brand-Gruwel, S., \& Van Merriënboer, J. J. G. (2011). The fit between students' lesson perceptions and 
desires: Relations with student characteristics and the importance of motivation. Educational Research, 53, 439457.

Paas, F., Tuovinen, J. E., Tabbers, H., \& Van Gerven, P. W. M. (2003). Cognitive load measurement as a means to advance cognitive load theory. Educational Psychologist, 38(1), 63-71.

Richardson, G. P., \& Pugh, A. L. (1981). Introduction to system dynamics modeling. Portland, OR: Productivity Press.

Ross, S. M., Morrison, G. R., \& O’Dell, J. K. (1989). Uses and effects of learner control of context and instructional support in computer-based instruction. Educational Technology Research and Development: ETR \& D, 37(4)), 29-39.

Salden, R. J. C. M., Paas, F., Broers, N. J., \& Van Merriënboer, J. J. G. (2004). Mental effort and performance as determinants for the dynamic selection of learning tasks in air traffic control training. Instructional Science, 32, 153-172.

Schnackenberg, H. L., \& Sullivan, H. J. (2000). Learner control over full and lean computer-based instruction under differing ability levels. Educational Technology Research and Development: ETR \& D, 48(2), 19-35. doi:10.1007/BF02313399

Shin, E. C., Schallert, D. L., \& Savenye, W. C. (1994). Effects of learner control, advisement, and prior knowledge on young students' learning in a hypertext environment. Educational Technology Research and Development: ETR \& D, 42(1), 33-46.

Topping, K. (2003). Self and peer assessment in school and university: Reliability, validity and utility. In M. Segers, F. Dochy, \& E. Cascallar (Eds.), Optimising new modes of assessment: In search of qualities and standards (pp. 55-87). Dordrecht, The Netherlands: Kluwer Academic Publishers.
Van Merriënboer, J. J. G. (1997). Training complex cognitive skills: A four-component instructional design model for technical training. Englewood Cliffs, NJ: Educational Technology Publications.

Van Merriënboer, J. J. G., \& Kester, L. (2008). Whole-task models in education. In J. M. Spector, M. D. Merrill, J. J. G. Van Merriënboer, \& M. P. Driscoll (Eds.), Handbook of research on educational communication and technology (pp. 441-456). New York, NY: Routledge/Taylor \& Francis Group.

Van Merriënboer, J. J. G., \& Kirschner, P. A. (2013). Ten steps to complex learning (2nd Rev ed.). New York, NY: Taylor \& Francis.

Van Merriënboer, J. J. G., Kirschner, P. A., \& Kester, L. (2003). Taking the load of a learner's mind: Instructional design for complex learning. Educational Psychologist, $38(1), 5-13$

Van Merriënboer, J. J. G., Sluijsmans, D., Corbalan, G., Kalyuga, S., Paas, F., \& Tattersall, C. (2006). Performance assessment and learning task selection in environments for complex learning. In J. Elen \& E. Clark (Eds.), Handling complexity in learning environments: Theory and research (pp. 201-220). Oxford, UK: Elsevier.

Vandewaetere, M. C., \& Clarebout, G. (2011). Can instruction as such affect learning? The case of learner control. Computers and Education, 57, 2322-2332. doi:10.1016/ j.compedu.2011.05.020

Vandewaetere, M. C., Vandercruysse, S., \& Clarebout, G. (2012). Learners' perceptions and illusions of adaptivity in computer-based learning environments. Educational Technology Research and Development: ETR \& D, 60(2), 307324. doi:10.1007/s11423-011-9225-2

Winters, F. I., Greene, J. A., \& Costich, C. M. (2008). Selfregulation of learning within computer-based learning environments: A critical analysis. Educational Psychology Review, 20, 429-444. doi:10.1007/s10648-008-9080-9 